\title{
Enhanced Active Power Filter Action for Renewable Power Generation Systems
}

\author{
Sayini Harish Naidu ${ }^{1}$, Narra Narender Reddy ${ }^{2}$ \\ ${ }^{1}$ Sri Venkateswara Engineering College, Suryapet, Nalgonda District, Telangana State, India \\ ${ }^{2}$ Assistant Professor, Sri Venkateswara engineering college, Suryapet, Nalgonda District, Telangana State, India
}

\begin{abstract}
An active power filter implemented with a four-leg voltage-source inverter using a predictive control scheme is presented. The application of a four-leg voltage-source inverter allows the compensation of current harmonic components, as well as unbalanced current generated by single-phase nonlinear loads. A detailed simple mathematical model of the active power filter, including the effect of the equivalent power system impedance, is derived and used to design the predictive control algorithm. The compensation performance of the proposed active power filter and the associated control scheme under steady state and transient operating conditions is demonstrated through simulations and experimental results.
\end{abstract}

Keywords: Active power filter, current control, four-leg converters, predictive control

\section{Introduction}

Renewable Power generation affects power quality due to its nonlinearity, since solar generation plants and wind power generators must be connected to the grid through high-power static PWM converters [1]. The non uniform nature of power generation directly affects voltage regulation and creates voltage distortion in power systems. Although active power filters implemented with three-phase four-leg voltage-source inverters (4L-VSI) have already been presented in the technical literature [2]-[6], the primary contribution of this paper is a predictive control algorithm designed and implemented specifically for this application. Traditionally, active power filters have been controlled using pre tuned controllers, such as PI-type or adaptive, for the current as well as for the dc-voltage loops [7], [8]. PI controllers must be designed based on the equivalent linear model, while predictive controllers use the nonlinear model, which is closer to real operating conditions. An accurate model obtained using predictive controllers improves the performance of the active power filter, especially during transient operating conditions, because it can quickly follow the current-reference signal while maintaining a constant dcvoltage. So far, implementations of predictive control in power converters have been used mainly in induction motor drives. In the case of motor drive applications, predictive control represents a very intuitive control scheme that handles multivariable characteristics, simplifies the treatment of dead-time compensations, and permits pulse-width modulator replacement. However, these kinds of applications present disadvantages related to oscillations and instability created from unknown load parameters. One advantage of the proposed algorithm is that it fits well in active power filter applications, since the power converter output parameters are well known. These output parameters are obtained from the converter output ripple filter and the power system equivalent impedance. The converter output ripple filter is part of the active power filter design and the power system impedance is obtained from well-known standard procedures. In the case of unknown system impedance parameters, an estimation method can be used to derive an accurate $R-L$ equivalent impedance model of the system.

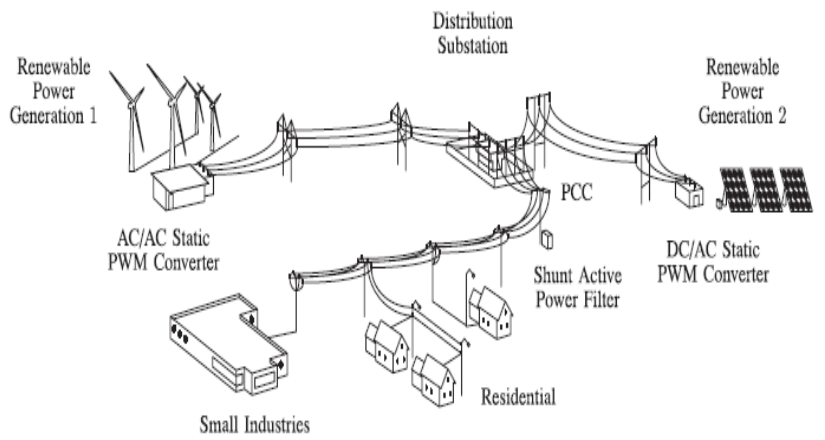

Figure 1: Stand-alone hybrid power generation system with a shunt active power filter.

This paper presents the mathematical model of the 4L-VSI and the principles of operation of the proposed predictive control scheme, including the design procedure. The complete description of the selected current reference generator implemented in the active power filter is also presented. Finally, the proposed active power filter and the effectiveness of the associated

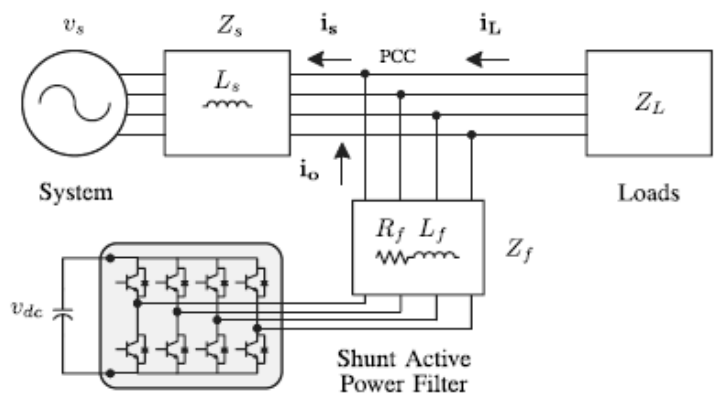

Figure 2: Three-phase equivalent circuit of the shunt active power filter.

control scheme compensation are demonstrated through simulation and validated with experimental results obtained in a $2 \mathrm{kVA}$ laboratory prototype. 


\section{International Journal of Science and Research (IJSR)}

ISSN (Online): 2319-7064

Index Copernicus Value (2013): 6.14 | Impact Factor (2015): 6.391

\section{Four-leg converter model}

Fig. 1 shows the configuration of a typical power distribution system with renewable power generation. It consists of various types of power generation units and different types of loads. Renewable sources, such as wind and sunlight, are typically used to generate electricity for residential users and small industries. Both types of power generation use ac/ac and dc/ac static PWM converters for voltage conversion and battery banks for long term energy storage. These converters perform maximum power point tracking to extract the maximum energy possible from wind and sun. The electrical energy consumption behavior is random and unpredictable, and therefore, it may be single- or three-phase, balanced or unbalanced, and linear or nonlinear.

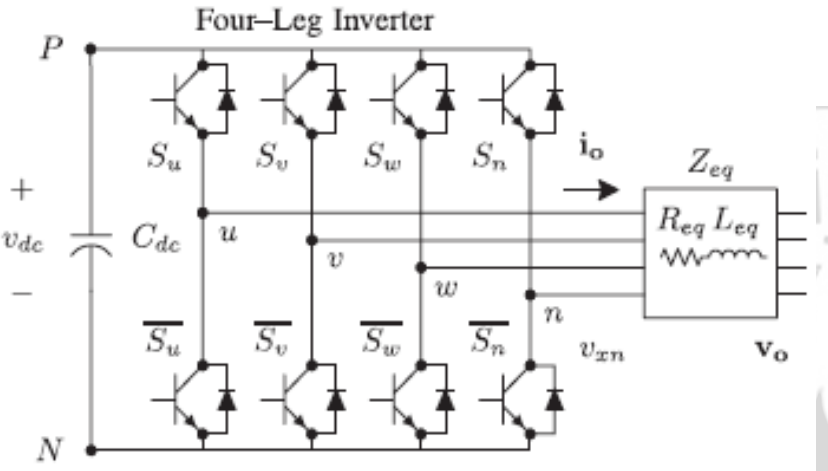

Figure 3: Four-leg PWM-VSI topology.

An active power filter is connected in parallel at the point of common coupling to compensate current harmonics, current unbalance, and reactive power. It is composed by an electrolytic capacitor, a four-leg PWM converter, and a firstorder output ripple filter, as shown in Fig. 2. This circuit considers the power system equivalent impedance $Z s$, the converter output ripple filter impedance $Z f$, and the load impedance $Z L$. The four-leg PWM converter topology is shown in Fig. 3. This converter topology is similar to the conventional three-phase converter with the fourth leg connected to the neutral bus of the system. The fourth leg increases switching states from 8 (23) to 16 (24), improving control flexibility and output voltage quality, and is suitable for current unbalanced compensation.

\section{Active Power filter Performance}

\subsection{Digital Predictive Current Control}

The block diagram of the proposed digital predictive current control scheme is shown in Fig. 4. This control scheme is basically an optimization algorithm and, therefore, it has to be implemented in a microprocessor. Consequently, the analysis has to be developed using discrete mathematics in order to consider additional restrictions such as time delays and approximations.

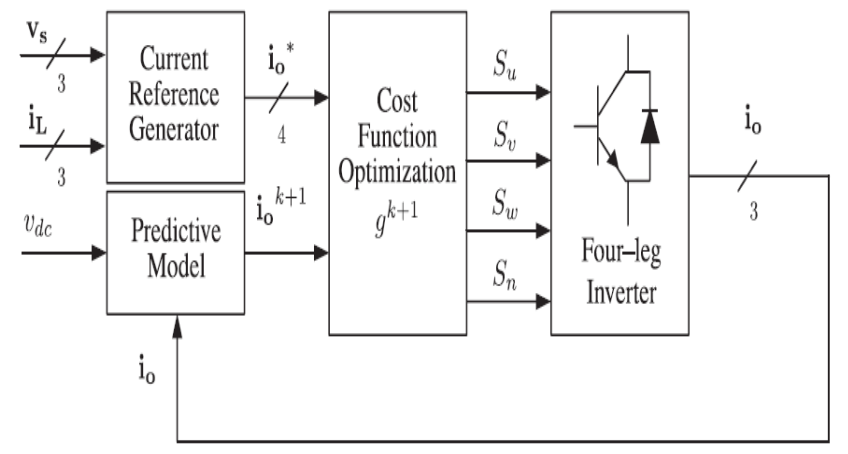

Figure 3.1: Predictive digital current control block diagram.

The main characteristic of predictive control is the use of the system model to predict the future behavior of the variables to be controlled. The controller uses this information to select the optimum switching state that will be applied to the power converter, according to predefined optimization criteria.

\subsection{DC-Voltage Control}

The dc-voltage converter is controlled with a traditional PI controller. This is an important issue in the evaluation, since the cost function is designed using only current references, in order to avoid the use of weighting factors. Generally, these weighting factors are obtained experimentally, and they are not well defined when different operating conditions are required. Additionally, the slow dynamic response of the voltage across the electrolytic capacitor does not affect the current transient response. For this reason, the PI controller represents a simple and effective alternative for the dcvoltage control.

The dc-voltage remains constant until the active power absorbed by the converter decreases to a level where it is unable to compensate for its losses. The active power absorbed by the converter is controlled by adjusting the amplitude of the active power reference signal ie, which is in phase with each phase voltage.

\subsection{Current Reference Generation}

A $d q$-based current reference generator scheme is used to obtain the active power filter current reference signals. This scheme presents a fast and accurate signal tracking capability. This characteristic avoids voltage fluctuations that deteriorate the current reference signal affecting compensation performance. The current reference signals are obtained from the corresponding load currents as shown in Fig. 4. This module calculates the reference signal currents required by the converter to compensate reactive power, current harmonic, and current imbalance. The displacement power factor $(\sin \varphi(L))$ and the maximum total harmonic distortion of the load $(\operatorname{THD}(L))$ defines the relationships between the apparent power required by the active power filter, with respect to the load, as shown where the value of $\operatorname{THD}(L)$ includes the maximum compensable harmonic current, defined as double the sampling frequency $f s$. The frequency of the maximum current harmonic component that can be compensated is equal to one half of the converter switching frequency. 


\section{International Journal of Science and Research (IJSR) \\ ISSN (Online): 2319-7064}

Index Copernicus Value (2013): 6.14 | Impact Factor (2015): 6.391

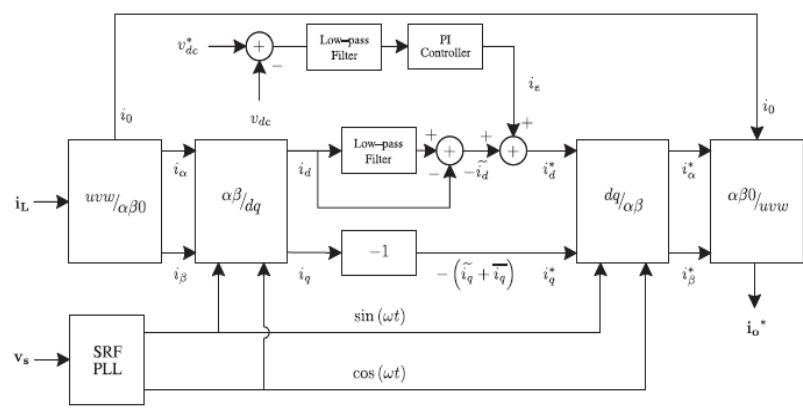

Figure 3.2: $d q$-based current reference generator block diagram

The $d q$-based scheme operates in a rotating reference frame; therefore, the measured currents must be multiplied by the $\sin (w t)$ and $\cos (w t)$ signals. By using $d q$-transformation, the $d$ current component is synchronized with the corresponding phase-to-neutral system voltage, and the $q$ current component is phase-shifted by $90^{\circ}$. The $\sin (w t)$ and $\cos (w t)$ synchronized reference signals are obtained from a synchronous reference frame (SRF) PLL. The SRF-PLL generates a pure sinusoidal waveform even when the system voltage is severely designed to avoid phase voltage unbalancing, harmonics (i.e., less than $5 \%$ and $3 \%$ in fifth and seventh, respectively), and offset caused by the nonlinear load conditions and measurement errors.

A low-pass filter (LFP) extracts the dc component of the phase currents id to generate the harmonic reference components - $i d$. The reactive reference components of the phase-currents are obtained by phase-shifting the corresponding ac and dc components of $i q$ by $180^{\circ}$. In order to keep the dc-voltage constant, the amplitude of the converter reference current must be modified by adding an active power reference signal ie with the $d$-component, as will be explained in Section IV-A.

The resulting signals are transformed back to a three-phase system by applying the inverse Park and Clark transformation.

\section{Advantages}

1. Consumer electronics.

2. Domestic appliances.

3. Large range of industrial applications.

4. Fluorescent lamps \&phase angle controlled lamp dimmers.

5. Three phase converters.

6. Arc welding, electric furnaces, electrolytic processes.

7. Industrial applications like variable speed drives.

8. improving power quality and harmonic elimination.

\section{Simulation Circuit}

A simulation model for the three-phase four-leg PWM converter with the parameters shown in Table I has been developed using MATLAB-Simulink. The objective is to verify the current harmonic compensation effectiveness of the proposed control scheme under different operating conditions. A six-pulse rectifier was used as a nonlinear load.
The proposed predictive control algorithm was programmed using an S-function block that allows simulation of a discrete model that can be easily implemented in a real-time interface (RTI) on the dSPACE DS1103 R\&D control board. Simulations were performed considering a $20[\mu \mathrm{s}]$ of sample time. In the simulated results shown in Fig. 8, the active filter starts to compensate at $t=t 1$. At this time, the active power filter injects an output current iou to compensate current harmonic components, current unbalanced, and neutral current simultaneously. During compensation, the system currents is show sinusoidal waveform, with low total harmonic distortion (THD $=3.93 \%)$. At $t=t 2$, a three-phase balanced load step change is generated from 0.6 to 1.0 p.u. The compensated system currents remain sinusoidal despite the change in the load current magnitude. Finally, at $t=t 3$, a single-phase load step change is introduced in phase $u$ from 1.0 to 1.3 p.u., which is equivalent to an $11 \%$ current imbalance. As expected on the load side, a neutral current flows through the neutral conductor ( $i L n)$, but on the source side, no neutral current is observed (isn ). Simulated results show that the proposed control scheme effectively eliminates unbalanced currents.
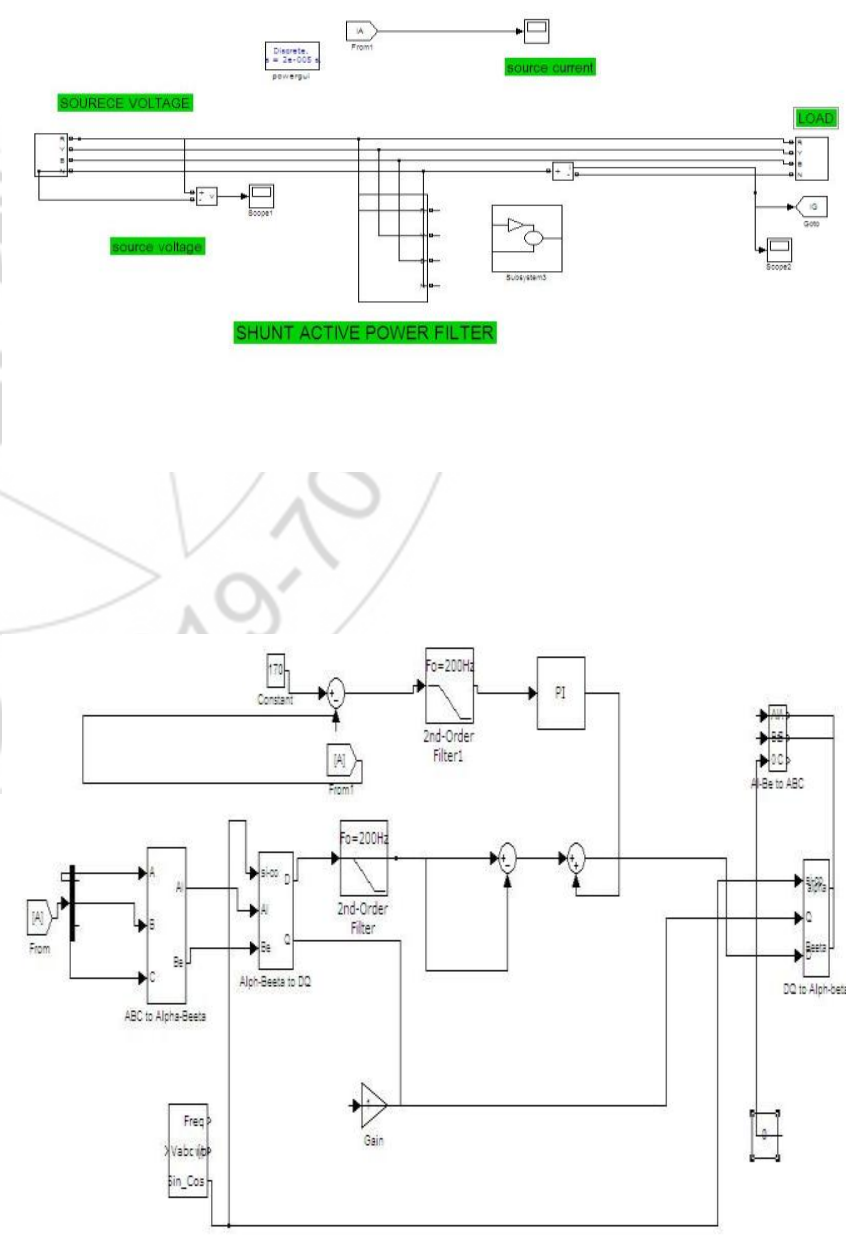

Fig 5. Simulation Block Diagram

The power electronics library of simulation contains diodes, thyristors, MOSFET and IGBT. These several blocks interconnected with each other to form Three Phase Bridges. 


\section{International Journal of Science and Research (IJSR) \\ ISSN (Online): 2319-7064}

Index Copernicus Value (2013): 6.14 | Impact Factor (2015): 6.391

Simulation of $3 \mathrm{HP}, 4$ pole motor is done with a inverter using Pulse Width Modulation (PWM) technique. These machines can be used to simulate electromechanical transient in an electrical network when combined with linear and non linear elements such as transformer line loads, breakers, etc. for simulation of drives they are combined with power electronics devices.

Frequency and amplitude of output voltage is varied by using PWM technique and these controlled voltage and frequency are used to control motor speed.

\section{Waveform Analysis}

Fig. 6 shows Load current waveforms of the Shunt active power filter

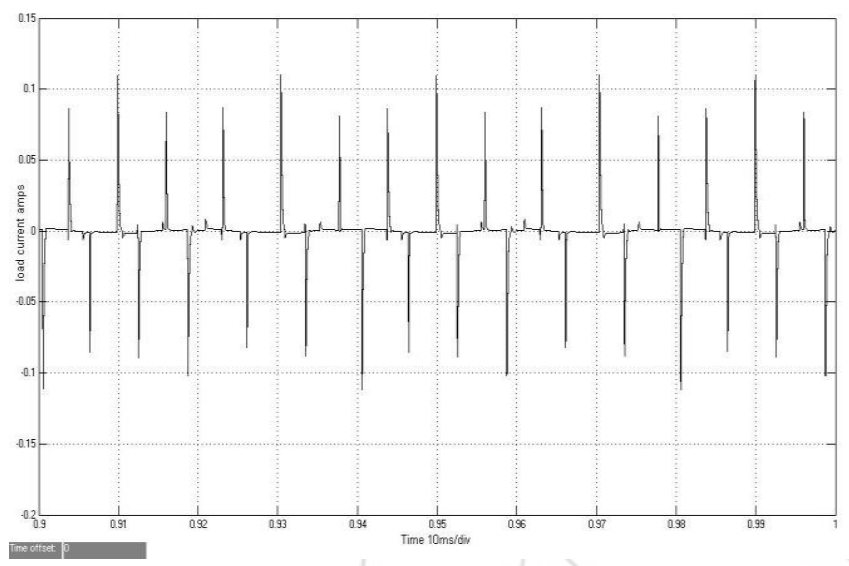

Figure 6: Load current

\section{Result}

The compensation effectiveness of the active power filter is corroborated in a $2 \mathrm{KVA}$ experimental setup. A six-pulse rectifier was selected as a nonlinear load in order to verify the effectiveness of the current harmonic compensation. A step load change was applied to evaluate the transient response of the dc voltage loop. Finally, an unbalanced load was used to validate the performance of the neutral current compensation. Because the experimental implementation was performed on a dSPACE I/O board, all I/O Simulink blocks used in the simulations are $100 \%$ compatible with the dSPACE system capabilities. The complete control loop is executed by the controller every $20 \mu$ s, while the selected switching state is available at $16 \mu \mathrm{s}$. An average switching frequency of $4.64 \mathrm{kHz}$ is obtained. The line currents remain sinusoidal and the dc-voltage returns to its reference with a typical transient response of an underdamped second-order system (maximum overshoot of 5\% and two cycles of settling time). In this case, a step load change is applied from 0.6 to 1.0 p.u. Finally, the load connected to phase $u$ was increased from 1.0 to 1.3 p.u. The corresponding waveforms are shown in Fig.4 Fig.4 shows that the active filter is able to compensate the current in the neutral conductor with fast transient response.

Moreover, Fig.4 shows that the system neutral current is effectively compensated and eliminated, and system currents remain balanced even if an $11 \%$ current imbalance is applied.

\section{Conclusion}

Improved dynamic current harmonics and a reactive power compensation scheme for power distribution systems with generation from renewable sources has been proposed to improve the current quality of the distribution system. Advantages of the proposed scheme are related to its simplicity, modeling, and implementation. The use of a predictive control algorithm for the converter current loop proved to be an effective solution for active power filter applications, improving current tracking capability, and transient response. Simulated and experimental results have proved that the proposed predictive control algorithm is a good alternative to classical linear control methods. The predictive current control algorithm is a stable and robust solution. Simulated and experimental results have shown the compensation effectiveness of the proposed active power filter.

\section{Acknowledgement}

The author would like to express his great thank to Mr. N. Narender Reddy (Head of the Department EEE \& Asst. Prof. of Sri Venkateswara Engineering College, India),Project Coordinator B.Venugopal Reddy ( Asst. Prof. of Sri Venkateswara Engineering College, India) \& my Staff for their valuable technical suggestion and full guidance towards completion of this paper.

\section{References}

[1] J. Rocabert, A. Luna, F. Blaabjerg, and P. Rodriguez, "Control of power converters in AC microgrids," IEEE Trans. Power Electron., vol. 27, no. 11, pp. 4734-4749, Nov. 2012.

[2] M. Aredes, J. Hafner, and K. Heumann, "Three-phase four-wire shunt active filter control strategies," IEEE Trans. Power Electron., vol. 12, no. 2, pp. 311-318, Mar. 1997.

[3] S. Naidu and D. Fernandes, "Dynamic voltage restorer based on a fourleg voltage source converter," Gener. Transm. Distrib., IET, vol. 3, no. 5, pp. 437-447, May 2009.

[4] N. Prabhakar and M. Mishra, "Dynamic hysteresis current control to minimize switching for three-phase four-leg VSI topology to compensate nonlinear load," IEEE Trans. Power Electron., vol. 25, no. 8, pp. 19351942, Aug. 2010.

[5] V. Khadkikar, A. Chandra, and B. Singh, "Digital signal processor implementation and performance evaluation of split capacitor, four-leg and three h-bridge-based threephase four-wire shunt active filters," Power Electron., IET, vol. 4, no. 4, pp. 463-470, Apr. 2011.

[6] F. Wang, J. Duarte, and M. Hendrix, "Grid-interfacing converter systems with enhanced voltage quality for microgrid application ;concept and implementation," IEEE Trans. Power Electron., vol. 26, no. 12, pp. 35013513, Dec. 2011.

[7] X.Wei, "Study on digital pi control of current loop in active power filter," in Proc. 2010 Int. Conf. Electr. Control Eng., Jun. 2010, pp. 4287-4290. 
[8] R. de Araujo Ribeiro, C. de Azevedo, and R. de Sousa, "A robust adaptive control strategy of active power filters for power-factor correction, harmonic compensation, and balancing of nonlinear loads," IEEE Trans. Power Electron., vol. 27, no. 2, pp. 718-730, Feb. 2012.

[9] J. Rodriguez, J. Pontt, C. Silva, P. Correa, P. Lezana, P. Cortes, and U. Ammann, "Predictive current control of a voltage source inverter," IEEE Trans. Ind. Electron., vol. 54, no. 1, pp. 495-503, Feb. 2007.

[10]P. Cortes, G. Ortiz, J. Yuz, J. Rodriguez, S. Vazquez, and L. Franquelo, "Model predictive control of an inverter with output $L C$ filter for UPS applications," IEEE Trans. Ind. Electron., vol. 56, no. 6, pp. 18751883, Jun. 2009.

[11] R. Vargas, P. Cortes, U. Ammann, J. Rodriguez, and J. Pontt, "Predictive control of a three-phase neutral-pointclamped inverter," IEEE Trans. Ind. Electron., vol. 54, no. 5, pp. 2697-2705, Oct. 2007.

[12] P. Cortes, A. Wilson, S. Kouro, J. Rodriguez, and H. Abu-Rub, "Model predictive control ofmultilevel cascaded H-bridge inverters," IEEE Trans. Ind. Electron., vol. 57, no. 8, pp. 2691-2699, Aug. 2010.

[13]P. Lezana, R. Aguilera, and D. Quevedo, "Model predictive control of an asymmetric flying capacitor converter," IEEE Trans. Ind. Electron., vol. 56, no. 6, pp. 1839-1846, Jun. 2009.

[14] P. Correa, J. Rodriguez, I. Lizama, and D. Andler, "A predictive control scheme for current-source rectifiers," IEEE Trans. Ind. Electron., vol. 56, no. 5, pp. 18131815, May 2009.

[15] M. Rivera, J. Rodriguez, B. Wu, J. Espinoza, and C. Rojas, "Current control for an indirect matrix converter with filter resonance mitigation," IEEE Trans. Ind. Electron., vol. 59, no. 1, pp. 71-79, Jan. 2012.

[16]P. Correa, M. Pacas, and J. Rodriguez, "Predictive torque control for inverter-fed induction machines," IEEE Trans. Ind. Electron., vol. 54, no. 2, pp. 1073 1079, Apr. 2007.

\section{Author Profile}

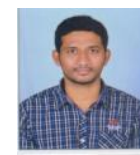

Sayini Harish Naidu received the B.Tech. degree in Electrical Engineering from Princeton engineering college, Rangareddy. He is now Presently pursuing M.Tech Power Electronics final year in Sri Venkateswara engineering college Suryapet.

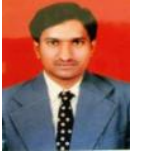

Mr. N Narender Reddy, presently working as Assistant professor and Head of the department in Sri Venkateswara engineering college Suryapet, Nalgonda (dist),T.S. India. He did his B.Tech degree in Electrical \& Electronics Engineering, P.G in High Voltage Engineering. Currently he is pursuing his Ph.D in K L University Vijayawada. He has a teaching experience of 10 years. His area of interest includes Smart grids and micro grids. 